\title{
autêntica
}

\author{
ARTIGOS
}

\section{Formação continuada de professores de Matemática no estado do Paraná a partir do Projeto Folhas}

Juliane Parcianello

\begin{abstract}
RESUMO: Esta pesquisa teve como objetivo principal compreender as contribuições do Projeto Folhas para a formação continuada de professores de Matemática. Desenvolveu-se mediante análise de trinta Folhas, material com fins didáticos produzidos pelos professores da rede estadual de ensino, sobre o conteúdo estruturante Funções, e foi efetivada por quinze questionários com professores/autores. O levantamento e a interpretação dos dados se deu pela Análise de Conteúdo, proposta por Bardin (2011). O Projeto Folhas possibilitou aos professores de Matemática o acesso à pesquisa a fim de ampliarem seus conhecimentos, bem como a produção colaborativa de textos de caráter teórico e metodológico sobre os conteúdos curriculares direcionados aos alunos do ensino médio e incentivo à carreira profissional, por meio de pontuação para a progressão funcional. Foi uma proposta importante que se configurou como recurso didático e de formação continuada de professores. Proporcionou oportunidade de formação, por meio da produção escrita, do processo de validação e da utilização do material, tanto para o professor que o produziu quanto para o que faz uso do material didático.
\end{abstract}

PALAVRAS-CHAVE: Projeto Folhas; Formação continuada de professores de Matemática; Ensino de Matemática.

\section{ABSTRACT}

This research had as main aim to understand the contribution of the Project Papers for the Continuing Education of Mathematics teachers. It was developed by the analysis of thirty Papers written about the structuring content Functions and it was held by fifteen questionnaires with the teachers. The closing and the interpretation of the data was held by the Analysis of the Content, proposed by Bardin (2011). The Project Papers enabled Mathematics teachers access to the research in order to enlarge their knowledge, as well the collaborative production of texts in theoretical and methodological character about the curriculum contents targeted to the High School students, stimulus to the professional career, through the punctuation to the functional progression. Was an important proposal that was set as a teaching tool and of Continuing Education for teachers. It enabled the opportunity of formation, through the written production, of the validation process and of the use of the material, both to the teacher who brought it forth and to the one who makes use of the teaching material.

KEYWORDS: Papers Project; Continuing education of Mathematics teachers, Mathematics teaching. 


\section{autêntica}

\section{INTRODUÇÃO}

Nas últimas décadas, no estado do Paraná, através da Secretaria Estadual de Educação (SEED/PR), foram desencadeados vários programas de formação continuada que demonstram preocupação com o desenvolvimento profissional e o aperfeiçoamento do professor da educação básica, sobretudo os desenvolvidos a partir do ano 2003, sob a égide da segunda e da terceira gestão do Governador Roberto Requião de Mello e Silva (2003-2006 e 2007-2010), que concebem o professor como sujeito epistemológico ativo no processo de formação.

As ações de formação continuada desenvolvidas objetivavam promover a melhoria da educação ofertada nas escolas públicas paranaenses. De forma geral, apresentam uma concepção mais democrática voltada para a participação ativa dos professores, a produção colaborativa de material de suporte pedagógico, o reconhecimento da escola como local de formação do professor e a reflexão crítica sobre a prática como fator de desenvolvimento profissional.

Entre os programas desenvolvidos direcionados à Educação Matemática e às questões e problemáticas próprias da disciplina está o Projeto Folhas. O Projeto Folhas foi uma das ações propostas pela SEED/PR na gestão 2003-2006, que se estendeu até 2010. Após esse período, o Projeto perdeu forças e não teve mais continuidade.

Implantado em todo o estado do Paraná no ano 2004, configurou-se como um projeto que possibilitava aos professores a pesquisa a fim de ampliarem seus conhecimentos e a produção colaborativa de textos de caráter teórico e metodológico sobre os conteúdos curriculares direcionados aos alunos do ensino médio.

Por meio do Projeto Folhas busca-se compreender a formação continuada de professores de Matemática no estado do Paraná entre os anos 2003 e 2010. O propósito é investigar de que forma o Projeto contribuiu para o aperfeiçoamento e a valorização profissional dos professores.

Utilizou-se a metodologia de Análise de Conteúdo para investigar os Folhas que tiveram maior número de publicações por conteúdo estruturante. Assim, foram analisados trinta Folhas do conteúdo estruturante Funções. Para compreender a implementação do Projeto junto aos professores da rede e detectar contribuições para a sua formação, realizou-se pesquisa com quinze professores/autores de Folhas do conteúdo estruturante Funções, por meio de questionário enviado por e-mail.

\section{PROJETO FOLHAS: COLABORAÇÃO ENTRE OS PARES PARA A ELABORAÇÃO DE MATERIAL PARA ALUNOS}

A constituição do Folhas materializa-se em textos com formato específico planejado para resultar em material didático. Por isso, ao produzir o Folhas, o professor/autor precisava atender a um conjunto de especificações obrigatórias.

Essas especificações estão detalhadas no Manual de Produção do Folhas publicado pela SEED/PR no ano 2006, que, de início, era o mesmo para todas as disciplinas. O Manual de Produção do Folhas: Matemática, publicado no ano 2007, contém as especificações gerais do manual anterior com inclusão das especificidades da disciplina. São elas: a) Problema do Folhas; b) Desenvolvimento teórico disciplinar e contemporâneo; c) Desenvolvimento teórico interdisciplinar; d) Propostas de atividades; e) Referências. 


\section{autêntica}

O item identificado como Problema do Folhas devia despertar no aluno o interesse em buscar e investigar os conteúdos necessários para a resolução ou discussão do que está proposto. Ou seja, é preciso "[...] que o aluno seja provocado, mobilizado a ler o Folhas, a estudar e pesquisar para encontrar a resposta" (PARANÁ, 2006a, p. 8).

Para isso, o problema inicial precisava ter relação com o conteúdo, o cotidiano do aluno (conhecimentos prévios, grupo social, mídia e outros) e estar no nível de ensino a que se destina (fundamental ou médio). Sua elaboração devia dar-se sob a ótica do aluno. Essa "[...] contextualização contribui para que o conhecimento ganhe significado para o aluno, para que aquilo que the parece sem sentido seja problematizado e apreendido" (PARANÁ, 2007, p. 5). Porém, esse deve ser apenas o ponto de partida da abordagem pedagógica, e a sequência deve proporcionar o desenvolvimento do pensamento e a sistematização do conhecimento.

Em relação à disciplina Matemática, o problema inicial deveria possibilitar a pesquisa em detrimento de respostas imediatas, a compreensão e apropriação do conhecimento matemático pelo estudante; o enunciado deveria fornecer indicativos que apontassem para o conhecimento matemático, para a solução do problema, e contemplar outras áreas do conhecimento, desde que permeado pelo conteúdo matemático. Assim, precisava ser elaborado a partir de situações do cotidiano, da História da Matemática e de situações hipotéticas (PARANÁ, 2007).

O desenvolvimento teórico precisava ser escrito de forma a oferecer suporte ao aluno para a solução do problema. Para isso, envolvia o conteúdo da disciplina, que devia estar adequado aos alunos e ao seu nível de ensino, visando a compreensão e a discussão do problema. Devia conter " [...] informações, convites e oportunidades para reflexões que permitam [permitissem] ao estudante elaborar algumas hipóteses e testá-las junto com seus colegas" (PARANÁ, 2007, p. 9).

A abordagem do conteúdo tinha que ser feita a partir de questões da atualidade, que levassem em conta a evolução e "[...] as aplicações ou usos contemporâneos destes conceitos, as práticas atuais referentes ao conhecimento que está sendo abordado" (PARANÁ, 2007, p.9).

De forma geral, o desenvolvimento teórico precisava favorecer o processo de ensino e a aprendizagem dos conceitos matemáticos. Segundo o texto de 2007, o desenvolvimento teórico do Folhas deve permitir que o estudante:

a) Aproprie-se do conhecimento matemático de modo que resolva problemas que surgem no seu cotidiano e aqueles elaborados ao longo da História da Matemática. b) Perceba que a matemática contribui para o desenvolvimento científico e tecnológico ao atuar nos vários campos das ciências. c) Conheça o valor sociológico da matemática que, por meio de soluções de problemas, provoque a crítica de questões sociais, políticas, econômicas e históricas. d) Tenha autonomia de transformação e criação, a partir dos conteúdos matemáticos aprendidos. e) Num processo de aquisição do conhecimento, em uma relação dialética entre o saber e o fazer matemática, pense matematicamente. f) Comunique-se matematicamente, ou seja, significa expressar verbalmente, por escrita ou por imagens, as ideias matemáticas (PARANÁ, 2007, p. 10).

Além de ter o conteúdo matemático como foco da produção, era preciso estabelecer relações com outras disciplinas. Assim, a abordagem do conteúdo acontecia de forma interdisciplinar, em que o objeto de estudo da Matemática tivesse relação com o objeto de estudo de outras disciplinas, o que possibilitaria ao aluno 
perceber a Matemática como uma disciplina que permeia outros campos do conhecimento, que faz parte do seu dia a dia. Essa relação também é importante para romper com a fragmentação do conhecimento gerado por um currículo disciplinar, como o caso das Diretrizes Curriculares da Educação Básica (DCEs).

Trabalhar a interdisciplinaridade não significa negar as especialidades e objetividade de cada disciplina, mas opor-se à concepção de que o conhecimento se processa em campos fechados em si mesmos. A interdisciplinaridade tem que respeitar o território de cada campo do conhecimento e distinguir os pontos que os unem e que os diferenciam. Essa é a condição necessária para detectar as áreas onde se possam estabelecer as conexões possíveis (PARANÁ, 2007, p.11, grifos do autor).

Dessa forma, o professor/autor, ao abordar determinado conteúdo, além de trabalhá-lo na visão da sua disciplina, devia explorar também a perspectiva de outras disciplinas. O desenvolvimento teórico disciplinar e interdisciplinar correspondia a um mesmo texto, em que o professor/autor devia preocupar-se com o "[...] conteúdo matemático que deve ser focalizado e a interdisciplinaridade deve ocorrer de forma natural e pertinente ao conteúdo matemático" (PARANÁ, 2007, p. 12).

O Folhas era e continua destinado aos alunos e envolve a participação ativa deles em todo o processo. Por isso, devia apresentar atividades que proporcionassem um maior aprofundamento no estudo dos conteúdos abordados. Para isso, as atividades eram elaboradas de forma a provocar e despertar o interesse para o estudo e a reflexão e eram incluídas ao longo de todo o texto. Tal direcionamento das atividades possibilitava novo ânimo à mobilização dada pelo problema inicial, indicando ao aluno os possíveis caminhos e alternativas para a continuidade da pesquisa (PARANÁ, 2007).

O Folhas necessitava de um suporte que o professor/autor buscaria em livros, revistas, trabalhos acadêmicos, artigos, sites, ilustrações, entre outros materiais citados e devidamente referenciados. Ao final, o professor/ autor produzia um texto contendo entre 8 e 12 páginas em folhas de papel A4, redigido de acordo com as normas de apresentação próprias do Projeto constantes nos manuais, respeitando os direitos autorais e a propriedade intelectual.

Como o Folhas foi proposto pela SEED/PR para a formação continuada do professor e envolveu o trabalho colaborativo entre os pares, seu formato e execução em âmbito estadual requeriam, para que o Projeto tivesse êxito, a participação de diferentes setores e a colaboração entre eles.

Por isso, sua execução deu-se em etapas distintas, articuladas entre si, com o objetivo de levar os professores à produção teórico-prática, à pesquisa e a se conceberem como produtores de conhecimento e saberes sobre sua profissão, além de produzirem material didático pedagógico destinado aos alunos, com o qual podem trabalhar os conteúdos curriculares que compõem as DCEs.

Dessa forma, o Projeto foi executado por meio das seguintes etapas: a) o professor produzia o Folhas e elaborava a sinopse; b) o Folhas era validado na escola; c) o professor fazia seu cadastro no Portal Dia a Dia Educação (caso ainda não fosse cadastrado) e verificava o cadastro dos validadores; d) o professor inscrevia o Folhas on-line no Portal Dia a Dia Educação; e) primeiramente preenchia todos os campos do formulário, depois digitava a sinopse e anexava o arquivo com o Folhas e os pareceres da validação na escola (PARANÁ, 2006a). Após inscrição, começava o processo de validação do Folhas em âmbito regional, por meio dos Núcleos Regionais de Educação (NREs), e estadual, pelos técnicos pedagógicos do Departamento de Educação Básica (DEB) da SEED/PR. 


\section{autêntica}

A validação configurava-se num processo de revisão, reflexão, sugestão, modificação, complementação e correção, quando necessária, objetivando ter como produto final um texto com consistência teórica (conceitual) dentro dos padrões da língua culta e com grau de complexidade adequado aos alunos a que se destinava.

O processo de colaboração propriamente dito ocorria em diferentes instâncias: na escola, com a participação de três professores, nos NREs, por meio das comissões, e na SEED/PR, por meio dos técnicos do DEB. A validação em âmbito escolar era feita por três professores, preferencialmente da mesma escola de atuação do professor/autor, cumprindo as seguintes exigências: "[...] um professor habilitado na mesma disciplina do autor do Folhas e dois professores habilitados nas outras duas disciplinas contempladas no desenvolvimento interdisciplinar" (PARANÁ, 2006a, p. 7).

Assim, a colaboração por meio da validação era iniciada quando o professor/autor entregava para cada um dos três professores validadores uma cópia do Folhas por ele produzido. Esses professores tinham a tarefa de analisar o Folhas, com vistas a validar o conteúdo e a abordagem da sua disciplina na perspectiva tanto do professor quanto do aluno. Nesse processo, os professores validadores tinham o auxílio do Manual de Produção e deveriam emitir parecer descritivo, digitado em editor de texto, em que constassem os seus comentários, as contribuições e as argumentações com justificativa e indicações de mudanças se necessário.

Nessa etapa cabia ao professor/autor fazer as adequações solicitadas e anexar os pareceres de validação junto ao arquivo que continha o Folhas no ato da inscrição no sistema on-line.

Após essa primeira etapa de validação, o NRE tinha 60 dias para submeter o Folhas à comissão de validação e enviar, via sistema on-line, o parecer para o autor/professor que, ao receber, tinha 30 dias para a reformulação e retorno ao NRE. Ao receber pela segunda vez o Folhas, o NRE tinha 30 dias para analisa reenviar à SEED/ PR ou devolver pela segunda vez ao autor/professor, que tinha mais 30 dias para os ajustes necessários e novo envio ao NRE, que emitia parecer final da comissão de validação encaminhando o Folhas à SEED/PR (PARANÁ, 2006a).

Ao chegar no DEB via on-line, o processo de validação já havia percorrido um longo caminho, com a colaboração de diversos atores. Assim, a validação nesse âmbito tinha o caráter de terminalidade do processo, e a comissão validadora tinha 60 dias para análise. Caso o Folhas fosse considerado adequado às exigências dos manuais, era validado e publicado no Portal Dia a Dia Educação. Caso contrário, era devolvido ao autor, que deveria fazer as adequações e iniciar um novo processo (PARANÁ, 2006a).

Para a publicação do Folhas no Portal Dia a Dia Educação, ele deveria ter cumprido todas as exigências do Manual Geral e do Manual por Disciplina e ter passado por todas as etapas de validação.

Segundo a SEED/PR, "[...] o processo de validação constitui-se como Formação Continuada" (PARANÁ, 2007, p. 18, grifos do autor). Por isso, havia grande preocupação com o registro dos pareceres por parte dos validadores nas diferentes instâncias. Assim, durante a realização do Projeto, foram elaborados pelo DEB/SEED/PR os manuais (geral e por disciplina) e os documentos Roteiro de Validação do Projeto Folhas e Parecer de Validação Folhas.

O Roteiro de Validação do Projeto Folhas foi concebido pela SEED/PR com objetivo de que o professor validador direcionasse sua orientação a aspectos que se limitassem ao Folhas em si (correção conceitual, 
formato, adequação pedagógica, linguagem voltada para o aluno), deixando de lado aspectos subjetivos, presentes, muitas vezes, pelo fato de os validadores na escola conhecerem o professor/autor (NERY, 2008).

O Parecer de Validação era o instrumento de registro utilizado pelos professores validadores pensado pela SEED/PR para viabilizar o processo de colaboração entre professor/autor e validador, em que este não se limitasse apenas a responder às perguntas do roteiro, mas que elaborasse, a partir do Manual, um texto dirigido ao professor/autor contendo justificativas de suas posições sobre o texto produzido, apontando sugestões de encaminhamento para o Folhas (NERY, 2008).

Para a SEED/PR, o momento de elaboração do parecer por parte dos validadores consistia em formação continuada, uma vez que, ao produzir o texto de validação com o auxílio do parecer, ele comprometia-se mais profundamente com o trabalho do outro professor. Para isso, esse professor validava o trabalho consultando o referencial teórico, fazia pesquisa, a fim de colaborar no processo, estudava e refletia sobre os conteúdos que o Folhas abordava e sobre a melhor metodologia para a sua abordagem em sala de aula.

Pensar sobre procedimentos de validação baseados no Manual de Produção, ou anteriormente no Roteiro de Validação, certamente desencadeia questões mais amplas de discussão, como concepção de ciência, educação, conhecimento e disciplina curricular, categorias que influem diretamente a prática docente e que, por isso, devem ser objeto de reflexão (NERY, 2008, p.57).

O cuidado tomado pela SEED/PR em relação à produção do Folhas e dos pareceres descritivos por parte dos validadores devia-se também, mas não somente, ao fato de que as duas ações estavam relacionadas à pontuação para progressão na carreira.

Os autores e validadores das escolas, do NRE e da SEED/PR recebiam pontuação pela produção de material didático/pedagógico para utilização na rede estadual de educação básica e profissional da seguinte forma: a) o autor de Folhas publicado no portal Dia a Dia Educação recebia 6,0 pontos, sendo o máximo de dois Folhas (12 pontos), no período avaliado; b) para o autor validador de Folhas, 1,0 ponto por Folhas validado e publicado no portal Dia a Dia Educação, com o limite de três Folhas (3,0 pontos) no período avaliado; c) para o autor de Folhas, avaliador do NRE e da SEED/PR: 0,5 ponto por Folhas validado, até o limite de 10 Folhas (5,0 pontos) no período avaliado (PARANÁ, 2006b).

Esse Projeto de Formação Continuada propunha aos professores da rede uma metodologia própria de produção de material didático de cunho colaborativo, em que era viabilizada " [...] a pesquisa dos saberes e fundamentos teórico-metodológicos das disciplinas que compõem a matriz curricular da Educação Básica da escola pública paranaense" (PARANÁ, 2007, p. 1).

A SEED/PR esperava que a proposição do Projeto Folhas, por meio da metodologia de produção de material didático, fomentasse a prática da pesquisa entre os professores no cotidiano escolar e viabilizasse a implantação das DCEs da rede pública de ensino do estado do Paraná (PARANÁ, 2006a).

O produto final de todo o processo de produção pensado para o Folhas eram textos - em forma de material didático dirigido aos alunos da educação básica - cujo autor era o professor da rede pública estadual em colaboração com seus pares na escola, no NRE e na SEED/PR.

Para produzir o material, tanto o professor/autor quanto os seus colaboradores eram envolvidos num processo de pesquisa em que se discutiam o conteúdo disciplinar com base nas DCEs, a pertinência e precisão conceitual do texto e as atividades pedagógicas propostas aos alunos, assim como a elaboração, a revisão e as modificações necessárias. 


\section{autêntica}

Espera-se que a troca de ideias, entre autor e colaboradores, provoque um processo de interação importante para a Formação Continuada dos profissionais da educação, além de resultar em um Folhas com correção conceitual e gramatical, linguagem e grau de complexidade adequados aos estudantes do Ensino Fundamental e/ou Médio da escola pública paranaense (PARANÁ, 2007, p. 1).

De acordo com o Relatório da Gestão 2003-2006 do DEB, os objetivos do Projeto Folhas eram: a) produção e publicação de recursos didáticos pelos profissionais da educação da rede pública estadual do Paraná; b) disponibilização de recursos didáticos produzidos e validados de forma colaborativa pelos professores da rede pública estadual do Paraná, oferecidos gratuitamente aos estudantes e professores em forma de livro didático ou publicação eletrônica no Portal Dia a Dia Educação; c) desenvolvimento de uma cultura de pesquisa que seja capaz de inovar o conceito corrente de capacitação dos profissionais da educação (PARANÁ, 2006c). A produção e validação do Folhas leva ao exercício da pesquisa, reflexão e sistematização, constituindo-se como atividade de aprendizagem e formação continuada.

Ainda nesse documento, a proposição do Folhas é justificada pela necessidade de atender as demandas de materiais didático-pedagógicos de qualidade e de desenvolver uma cultura de pesquisa entre os profissionais da educação e de valorização da produção dos professores.

O Projeto é uma ação no sentido de romper a velha dicotomia entre pensar e fazer, reconhecendo o professor como sujeito que pensa, cria, produz trabalha com o conhecimento e valoriza sua ação reflexiva e sua prática. O professor produz seu material de aula, produz seu ensino, produz currículo, e é valorizado por isso (NERY, 2008, p. 136-137).

O Projeto Folhas caracterizou-se como ações de formação continuada, sendo a tônica, a valorização do profissional. Além disso, não podia ser enquadrado nas metodologias tradicionais de formação oferecidas aos professores, e não tinha caráter pontual, mas primava pela continuidade dos trabalhos, objetivando instituir uma cultura de formação continuada autônoma entre os professores da rede estadual.

\section{DISCUSSÃO DOS RESULTADOS}

O texto do Folhas é estruturado em torno dos conteúdos curriculares. Cada Folhas contempla um conteúdo estruturante específico (conhecimento de grande amplitude fundamental para a compreensão do objeto de estudo), que se subdivide em conteúdos básicos (conhecimentos fundamentais para cada série), e é aprofundado por meio do trabalho propriamente dito com os conteúdos específicos (desdobramento dos conteúdos básicos em unidades menores adequadas ao tempo e espaço escolar) (PARANÁ, 2008).

Esta pesquisa foi realizada junto aos professores/autores de Folhas do conteúdo estruturante Funções. Em relação aos conteúdos abordados por eles, o que diferencia uma produção da outra são os conteúdos básicos. Os professores/autores pesquisados afirmam que seus Folhas versam sobre função afim, função exponencial, função logarítmica, progressão aritmética, progressão geométrica e razões trigonométricas.

Para os professores/autores, a escolha pelo conteúdo estruturante Funções deu-se principalmente porque esse é um conteúdo de difícil entendimento por parte dos alunos, e alguns dos conteúdos básicos são de pouca aplicabilidade prática. Por isso, era preciso mostrar a razão de sua aprendizagem, o que, para eles, poderia ser realizado por meio de estratégia de ensino contextualizada com a realidade dos alunos, conforme se observa em suas palavras: 


\section{autêntica}

Precisava encontrar algo que desse uma razão para o estudo de funções (Professor/autor E).

O Folhas contempla o conteúdo estruturante Funções, com foco na função afim. Na época em que foi escrito, eu trabalhava com primeiros anos do ensino médio e percebia a dificuldade que os estudantes tinham em compreender conceitos relacionados a Funções, por isso a preocupação em trabalhar esse conteúdo de forma interessante (Professor/autor F).

A principal preocupação dos professores/autores ao escreverem era relacionar os conteúdos matemáticos constantes nas DCEs às situações cotidianas, como se percebe em suas afirmações a respeito do propósito de seus Folhas:

Trabalhar um conteúdo matemático de forma interessante, envolvendo uma situação cotidiana, que despertasse a curiosidade, a pesquisa e a participação efetiva dos estudantes (Professor/autor F).

Demonstrar a aplicabilidade dos conteúdos, sua contextualização e a relação com outras áreas do conhecimento (Professor/autor H).

O Projeto Folhas foi concebido com a intenção de articular os conteúdos específicos e básicos de cada disciplina e esses com os demais conteúdos das outras disciplinas, permitindo que o trabalho fosse complementado por meio da relação interdisciplinar com outras áreas do conhecimento e dos conteúdos estruturantes de cada área entre si. Isso permitiu a

[...] reflexão de como a Matemática se relaciona com outras áreas de conhecimento e como isso pode ser discutido na construção de um conceito matemático, ou ainda, de como a Matemática pode ajudar a resolver problemas de outras áreas de conhecimentos (Professor/autor O).

O conhecimento não se restringe somente à disciplina. Por isso, essas relações são fundamentais para a compreensão da totalidade que envolve a realidade. Os textos do Folhas apresentam relacionamento interdisciplinar e dos conteúdos matemáticos objetivando

[...] articular os conteúdos estruturantes com os conteúdos específicos em relações de interdependências que enriqueçam o processo pedagógico de forma a abandonar abordagens fragmentadas, como se os conteúdos de ensino existissem em patamares distintos e sem vínculos (PARANÁ, 2008, p. 62).

A produção do Folhas teve como propósito iniciar a abordagem dos conteúdos a partir de um problema vinculado ao cotidiano do aluno. Isso evidencia que os conteúdos devem ser assumidos como conhecimentos traduzidos em conceitos, teorias e ideias originadas historicamente por meio da síntese da realidade material e social.

Ao elaborar o Folhas, o professor/autor teve por finalidade proporcionar aos alunos os saberes produzidos historicamente por meio das relações sociais. Nesse processo de pesquisar, estudar e refletir sobre os conteúdos, a relação destes com a realidade e os meios adequados para mediar o processo de transmissão-assimilação dos conhecimentos, o professor realiza trabalho que, ao mesmo tempo em que transforma a realidade adaptando-a às suas intencionalidades, também é transformado por meio das relações que estabelece nesse processo de produção não material, de modo que se autoproduz, aperfeiçoando sua concepção de mundo, de educação, de escola, de prática e de aluno (SAVIANI, 2005). 


\section{autêntica}

O ponto nodal da formação continuada defendida pelo Projeto Folhas é a formação capaz de propiciar aos professores mudanças em sua prática educativa por meio do trabalho realizado por eles mesmos em colaboração com seus pares, pois em sua "[...] práxis produtiva o homem se produz, forma ou transforma a si mesmo" (VÁZQUEZ, 1990, p. 198).

Ao mesmo tempo que desse modo atua sobre a natureza exterior a ele e a transforma - diz Marx em O Capital-, transforma sua própria natureza desenvolvendo as potências que nele dormitam e submetendo o jogo de suas forças a sua própria disciplina (VÁZQUEZ, 1990, p. 198, grifos do autor).

Na conjuntura atual, a educação é premente para que o sujeito produza a sua existência, ou seja, é uma condição do e para o processo de trabalho material, tornando-se ela própria um processo de trabalho que assume caráter de princípio educativo, pois "[...] o homem não se faz homem naturalmente; ele não nasce sabendo ser homem, vale dizer, ele não nasce sabendo sentir, pensar, avaliar, agir. Para saber pensar e sentir; para saber querer, agir ou avaliar é preciso aprender, o que implica o trabalho educativo" (SAVIANI, 2005, p.7).

Vale ressaltar que o Folhas, em sua estrutura, procura garantir a aprendizagem dos conteúdos por meio de um trabalho educativo, com metodologia diferenciada da comumente usada em sala de aula, considerando o aluno como protagonista no processo de ensino-aprendizagem. Essa postura do professor/autor revela a concepção de trabalho educativo que converge para a compreensão de que o trabalho educativo "[...] é o ato de produzir, direta e intencionalmente, em cada indivíduo singular, a humanidade que é produzida histórica e coletivamente pelo conjunto dos homens" (SAVIANI, 2005, p.13).

Compreende-se, a partir da análise das trinta produções, que, para os professores/autores dos Folhas do ensino médio, a educação representa uma estratégia desenvolvida pela humanidade para chegar "[...] à identificação dos elementos culturais que precisam ser assimilados pelos indivíduos da espécie humana para que eles se tornem humanos e, de outro lado e concomitante, à descoberta das formas mais adequadas para atingir este objetivo (SAVIANI, 2005, p.13). Nesse contexto, a educação Matemática configura-se em "práxis que envolve o domínio do conteúdo específico (a matemática) e o domínio de ideias e processos pedagógicos relativos à transmissão/assimilação[...] do saber matemático escolar" (FIORENTINI; LORENZATO, 2012 , p. 5, grifos dos autores).

Desse modo, o professor/autor, ao elaborar o problema inicial do Folhas e refletir sobre os conceitos e as estratégias que precisariam ser mobilizadas pelos alunos para responder a ele, realizou exercício possível de levar ao entendimento de que a disciplina que leciona, a Matemática, foi e continua sendo "[...] uma estratégia desenvolvida pela espécie humana ao longo da história para explicar, para entender, para manejar e conviver com a realidade [...] dentro de um contexto natural e cultural" (D'AMBROSIO, 2010, p. 7).

Em decorrência, o papel da escola apresentado nos textos Folhas é a socialização do saber sistematizado; em outras palavras, "a escola existe, pois, para propiciar a aquisição dos instrumentos que possibilitam o acesso ao saber elaborado (ciência), bem como o próprio acesso aos rudimentos desse saber" (SAVIANI, 2005, p. 15).

É a instituição escolar que no mundo moderno e contemporâneo apresenta-se como a forma de acesso aos conhecimentos e é a escola pública, gratuita e universal que se constitui como a alternativa que assegura o acesso à maioria da população, do contato com a cultura formal e com o conhecimento científico (ARCO-VERDE, 2004, p.1). 
É notável a preocupação dos professores/autores com a aprendizagem dos conteúdos, o que permite afirmar que identificam e assumem a necessidade que os alunos da escola pública (ou seja, de camadas populares) têm de adquirir esses saberes para superar sua condição de explorados, pois, somente assim, por meio do acesso ao conhecimento historicamente produzido, muitas vezes exclusivo das classes dominantes (que o utiliza para perpetuar a dominação), poderão buscar a emancipação social. Ou seja, "[...] o dominado não se liberta se ele não vier a dominar aquilo que os dominantes dominam. Então, dominar o que os dominantes dominam é condição de libertação" (SAVIANI, 1999, p.66).

Os conteúdos são fundamentais e, sem conteúdos relevantes, conteúdos significativos, a aprendizagem deixa de existir, ela se transforma num arremedo, ela se transforma numa farsa. Parece-me, pois, fundamental que se entenda isso e que, no interior da escola, nós atuemos segundo essa máxima: a prioridade de conteúdos, que é a única forma de lutar contra a farsa do ensino. [...] o domínio da cultura constitui instrumento indispensável para a participação política das massas. Se os membros das camadas populares não dominam os conteúdos culturais, eles não podem fazer valer os seus interesses, porque ficam desarmados contra os dominadores, que se servem exatamente desses conteúdos culturais para legitimar e consolidar a sua dominação (SAVIANI, 1999, p.66).

Tais constatações permitem afirmar que os professores/autores concebem o homem como um ser que se constituí nas relações sociais e, por isso, é determinado socialmente. Porém, em relação dialética ele também determina a sociedade com possibilidade de transformá-la, por meio de "[...] diversos atos orientados no sentido de sua transformação como ser social, e, por isso, destinados a mudar suas relações econômicas, políticas e sociais" (VÁZQUEZ, 1990, p. 200). Assim, por meio da apropriação dos conhecimentos historicamente produzidos pela humanidade, "interfere sobre a sociedade, podendo contribuir para a sua própria transformação" (SAVIANI, 2005, p. 93).

Ao conceber o homem como ser ativo capaz de transformar as relações sociais, os professores/autores mostram nas entrelinhas de seus textos que a sociedade é resultado de um processo de transformação dialética e está em constante mudança, em conformidade com o modo de produção vigente ao longo da história.

Mostrou-se a ênfase dada aos conteúdos escolares e o que essa ação materializada nos textos Folhas de ensino médio indica em relação às concepções dos professores/autores. Porém, não é possível omitir-se em relação à clara evidência de que o trabalho com os conteúdos vem como forma de superar o esvaziamento escolar provocado pelas políticas neoliberais implantadas nos governos anteriores.

Até o ano 2003, o currículo oficial das escolas paranaenses tinha como base os Parâmetros Curriculares Nacionais, documento que traz o ideário de que as modificações constantes na sociedade refletem na educação escolar, que deve formar sujeitos com competências e habilidades para o uso das novas tecnologias e com comportamento inovador perante os desafios impostos pela sociedade capitalista. Tal postura secundariza a importância dos conteúdos escolares, reduzindo-os a informações que constituem um saber imediato e utilitário, ou seja, concorrem para a formação de um sujeito adaptável ao mercado, flexível às leis do capital.

Perante esses fatos, as DCEs são idealizadas para superar tal distorção e retomar o trabalho com os conteúdos científicos na escola, sendo o Projeto Folhas uma das estratégias para viabilizar e implementar nova concepção de ensino e aprendizagem, que cumpriu com a finalidade de trabalhar os conteúdos aliados à perspectiva de transformação social.

A leitura das DCEs permite dizer que seu conteúdo teórico-metodológico está alinhado à Pedagogia HistóricoCrítica proposta por Saviani $(1999,2005)$. O Projeto Folhas representou uma das estratégias de implementação 


\title{
autêntica
}

das DCEs e, consequentemente, está alinhado à pedagogia em questão, o que fica comprovado pela estrutura do texto que o compõe.

Esse texto é formado por itens considerados obrigatórios como: a) problema; b) desenvolvimento teórico: contemporâneo-interdisciplinar; c) atividades; e d) referências. Essa estrutura assemelha-se aos passos do método de ensino proposto por Saviani:

\begin{abstract}
O ponto de partida seria a prática social $1^{\circ}$ passo, que é comum a professor e alunos. [...] O segundo passo [...] identificação dos principais problemas postos pela prática social. Chamemos a este segundo passo de problematização. Trata-se de detectar que questões precisam ser resolvidas no âmbito da prática social e, em consequência, que conhecimento é necessário dominar [...] Segue-se, pois, o terceiro passo [...] Trata-se de se apropriar dos instrumentos teóricos e práticos necessários ao equacionamento dos problemas detectados na prática social. [...] Chamemos, pois, este terceiro passo de instrumentalização. O quarto passo [...]Chamemos este quarto passo de Catarse [...] Trata-se da efetiva incorporação dos instrumentos culturais, transformados agora em elementos ativos de transformação social. O quinto passo [...] O ponto de chegada é a própria prática social, compreendida agora não mais em termos sincréticos pelos alunos. [...] a passagem da síncrese à síntese; em consequência, manifesta-se nos alunos a capacidade de expressarem uma compreensão da prática em termos tão elaborados quanto era possível ao professor (SAVIANI, 1999, p. 79-82, grifos do autor).
\end{abstract}

No Folhas, o problema é a primeira categoria que aparece, visto que ele segue as normas específicas do Projeto propostas pela SEED/PR. O primeiro passo, a prática social, foi realizado pelo professor/autor antes de pensar no problema, no momento em que ele refletiu e analisou os objetivos que precisava atingir junto aos alunos, ou seja, a "[...] prática social envolve uma antecipação do que the será possível fazer com alunos cujos níveis de compreensão ele não pode conhecer, no ponto de partida, senão de forma precária" (SAVIANI, 1999, p. 80).

Nessa etapa de elaboração do problema inicial, o professor/autor precisou pensar em situações que levassem à predisposição por parte dos alunos em aprender o conteúdo que pretendia ensinar. Assim, ao estabelecer a finalidade do Folhas que iria elaborar, levou em consideração que "[...] o educando deve ser desafiado, mobilizado, sensibilizado; deve perceber alguma relação entre o conteúdo e a sua vida cotidiana, suas necessidades, problemas e interesses" (GASPARIN, 2005, p. 15).

O problema do texto Folhas corresponde ao segundo passo do método de Saviani (1999), a problematização. $\mathrm{Na}$ elaboração do problema, o professor/autor procurou levantar uma problemática vinculada à realidade dos alunos, o que traz à tona as questões que precisam ser tratadas e resolvidas na prática social e quais conteúdos (conhecimentos) precisam ser mobilizados e aprendidos para dar respostas a essa problemática.

Esse é o momento em que o professor/autor coloca a prática social dos alunos a quem se destina o seu Projeto Folhas em questão, fazendo com que ela seja "[...] analisada, interrogada, levando em consideração o conteúdo a ser trabalhado e as exigências sociais de aplicação desse conhecimento" (GASPARIN, 2005, p. 36). De outro modo, pode-se dizer que, por meio do problema, o professor/autor criou a necessidade para que o aluno, através de reflexão, estudo, pesquisa e análise, busque o conhecimento, iniciando, dessa forma, o trabalho com o conteúdo sistematizado.

O terceiro passo do método, a instrumentalização, figura no texto Folhas no desenvolvimento teórico, contemporâneo e interdisciplinar em que o professor apresenta e desenvolve junto aos alunos os conteúdos 
(conhecimentos), instrumentos necessários para resolver o problema apresentado. Os conteúdos mobilizados para resolver o problema são apropriados pelos alunos através de "[...] sua transmissão direta ou indireta por parte do professor. Digo transmissão direta ou indireta porque o professor tanto pode transmiti-los diretamente como pode indicar os meios através dos quais a transmissão venha a se efetivar" (SAVIANI, 1999, p.81).

É nesse momento que o professor/autor do Folhas apresenta os conteúdos sistematizados aos "[...] alunos para que o assimilem e o recriem e, ao incorporá-lo, transformem-no em instrumento de construção pessoal e profissional" (GASPARIN, 2005, p. 53). Por meio da instrumentalização proporcionada pelo desenvolvimento teórico, contemporâneo e interdisciplinar do Folhas, o aluno pode apropriar-se criticamente da realidade, pois ela permite-Ihe superar o conhecimento imediato que traz de seu cotidiano, conduzindo ao entendimento da totalidade social.

O Folhas apresenta, ainda, atividades que, de acordo com exigência da SEED/PR, precisavam ser distribuídas ao longo do texto para "[...] reabilitar a mobilização alcançada pelo problema inicial, indicando ao aluno a continuidade da pesquisa, possibilitando o desenvolvimento de várias linguagens" (PARANÁ, 2007, p.12). Ao relacionar essa característica do texto com o método de Saviani, pode-se dizer que ela equivale ao quarto passo, a catarse. Pois, para resolver as atividades, os alunos precisam ter aprendido os conteúdos, ter adquirido os instrumentos historicamente produzidos que servem como ferramentas para a solução dos problemas, ou seja, é nesse momento que o aluno demonstra a "[...]expressão elaborada da nova forma de entendimento da prática social a que se ascendeu" (SAVIANI, 1999, p. 81).

Ao resolver as atividades presentes no Folhas, sejam elas exercícios, problemas ou pesquisas, o aluno "[...] traduz oralmente ou por escrito a compreensão que teve de todo o processo de trabalho. Expressa sua nova maneira de ver o conteúdo e a prática social. É capaz de entendê-los em um novo patamar, mais elevado, mais consistente e mais bem estruturado" (GASPARIN, 2005, p. 128).

Ocorre aqui a síntese entre o teórico e o prático que, entendido como práxis, proporciona a transformação da realidade social, ao mesmo tempo que transforma o sujeito que desenvolve a ação e através dela se desenvolve (VÁZOUEZ, 1990; GASPARIN, 2005; SAVIANI, 1999, 2005).

Ao final do processo pedagógico proposto pelo Folhas, objetiva-se que o aluno tenha domínio dos conteúdos trabalhados e que possa fazer uso deles em diferentes situações de seu dia a dia em busca de uma sociedade mais justa e igualitária. Isso corresponde ao quinto e último passo do método proposto por Saviani, a prática social. Os alunos, a partir do trabalho realizado, têm uma nova compreensão da prática, em termos mais elaborados, que Ihes permite entender o uso social e político desses conteúdos.

Nessa linha de pensamento, a teoria aprendida (conteúdos) não transforma a realidade, ou seja, haverá mudança quando esta fizer parte da ação prática de alunos e professores. Dessa forma,

[...] a teoria por si só não transforma o mundo real, torna-se prática quando penetra na consciência dos homens. Desse modo, ficam estabelecidos seus limites e a condição necessária para que se torne prática; por si só ela é inoperante e não pode substituir a ação, mas se torna força efetiva um "poder material" - quando é aceita pelos homens (VÁZQUEZ, 1990, p. 127).

Dito de outro modo, o ponto de chegada de todo o trabalho realizado pelo professor/autor do Folhas e seus alunos é a prática social final, em que ambos podem se "[...] posicionar de maneira diferente em relação à 


\section{autêntica}

prática, pois modificou sua maneira de entendê-la. Em consequência, sua prática também não seria a mesma. Seu pensar e agir podem passar a ter uma perspectiva transformadora da realidade" (GASPARIN, 2005, p. 8).

O Projeto Folhas constituiu uma proposta que se configurou como recurso didático e de formação continuada de professores capaz de incentivar e promover a participação ativa e consciente dos alunos sem deixar de lado o papel do docente na condução do processo de ensino-aprendizagem. Preocupa-se com os interesses dos alunos e com questões do cotidiano, mas está direcionado para além, para a sistematização do conhecimento, para a relação com a cultura historicamente produzida.

Os professores/autores caracterizam o Folhas como um material de apoio pedagógico, uma vez que suas produções, por se constituírem em exemplos de como trabalhar os conteúdos matemáticos de forma interdisciplinar, auxiliaram e auxiliam os professores que estão em sala de aula por meio de metodologias de ensino diferentes da tradicional, que podem ser utilizadas como estão apresentadas no Folhas ou serem adaptadas de acordo com a necessidade do professor e da turma. Assim, de acordo com os professores/ autores, o Folhas é um recurso didático que pode auxiliar os professores de diferentes maneiras:

Ao oferecer uma sequência didática que pode ser utilizada e adaptada de acordo com a necessidade da turma (Professor/autor C).

Mostrar que é possível pensar em uma aula de Matemática que seja diferente da aula tradicional (Professor/autor D).

São materiais didáticos que podem ser utilizados por outros professores interessados em inovar a prática. Trazem sugestões de atividades para a abordagem de conteúdos da Matemática, o estabelecimento de relações interdisciplinares e de ampliação de saberes por meio de consultas bibliográficas e de sites (Professor/autor K).

Exemplo de práticas que podem ser utilizadas, modificadas, adaptadas, e, ainda, podem inspirar a elaboração de outro Folhas (Professor/autor O).

Enquanto ação de formação continuada de professores, proporcionou a reflexão sobre a prática como forma de compreender as suas determinações, as suas limitações e, por meio da pesquisa, do estudo e da colaboração entre os pares, permitiu a busca de meios para melhorar e tornar o processo de ensino-aprendizagem significativo, com potencial crítico e transformador, pois, na medida em que desenvolve a prática, o professor/autor está pondo em questão as teorias que tem sobre a educação e o ensino. Nesse sentido, “[...] a prática não funciona como critério de validade da teoria, mas também como seu fundamento, já que permite superar suas limitações anteriores mediante seu enriquecimento com novos aspectos e soluções" (VÁZQUEZ, 1990, p. 225). Nas palavras dos professores/autores, o Folhas permitiu:

Refletir sobre a minha prática pedagógica num processo colaborativo ao elaborar textos pedagógicos. Foi importante para reflexão e mudança da minha prática pedagógica. Uma experiência de trabalho colaborativo (Professor/autor O).

Ao falar do processo de elaboração do Folhas, os professores/autores destacam benefícios e também algumas dificuldades. Para eles, foi uma experiência que marcou suas vidas profissionais, pois trouxe o desafio da leitura, do estudo, da pesquisa, da escrita, do trabalho em colaboração com colegas e a aprendizagem de novas metodologias de ensino. 


\section{autêntica}

Foi um processo de estudo, pesquisa e crescimento. Contribuiu para o meu conhecimento não apenas para sistematizar conceitos relacionados com Matemática (Professor/autor F).

Muito enriquecedor para o meu conhecimento e habilidade de pesquisa e produção de texto (Professor/autor I).

Foram experiências bastante enriquecedoras, pois as produções escritas, além de possibilitarem o aprofundamento de conteúdos da disciplina de Matemática e das temáticas que envolveram as relações interdisciplinares, permitiram-me retomar a prática da pesquisa acadêmica, bem como lançar novos olhares para o tratamento metodológico dos conteúdos. Além disso, a escrita do material fomentou a troca de ideias com outros professores, pois a produção ocorria de forma colaborativa (Professor/autor K).

Em relação às dificuldades, os principais aspectos evidenciados foram: a necessidade de pesquisas e leituras que, de acordo com os professores/autores pesquisados, não era hábito entre os professores; e a relação interdisciplinar obrigatória para a produção e a falta de orientador no processo de elaboração, visto que, para muitos, era primeira vez que escreviam um material no formato do Folhas. Isso fica evidenciado nas seguintes argumentações:

Foi um pouco difícil, muita leitura e pesquisas. Apesar de ter sido feito em dupla, valeu a experiência (Professor/autor A):

Foi difícil, não tínhamos orientador, encontrávamo-nos aos sábados, com pouco tempo para pesquisa e muitas dificuldades em vários aspectos (Professor/autor B).

Um tanto complicado, estava começando a questão de interdisciplinaridade e era tudo novo (Professor/autor N).

A contribuição do Projeto Folhas para a formação dos professores/autores fica evidenciada na medida em que eles argumentam que, por meio do processo de elaboração de seus Folhas, tiveram a oportunidade de aprofundar os conhecimentos em sua área de ensino (Matemática) assim como nas outras áreas que tinham relação interdisciplinar com o Folhas escrito por eles. Assim, eles desenvolveram o gosto pela leitura e pesquisa, mostrando que havia possibilidades de eles mesmos produzirem o seu material didático voltado para metodologias de ensino mais contextualizadas e dinâmicas, com finalidade de envolver os alunos e facilitar a aprendizagem. Conforme as palavras dos próprios professores/autores:

Contribuiu para [melhorar] minha capacidade de pesquisa e sistematização de conceitos relacionados à Matemática, para o uso do computador como ferramenta para a construção dos gráficos, com o estudo de estratégias de ensino. Além de conhecimentos relacionados com Química e Biologia, principalmente em relação à sustentabilidade (Professor/autor F).

Aprofundamento de meu conhecimento sobre os temas envolvidos, sobre o conhecimento e sobre interdisciplinaridade (Professor/autor I).

Contribuiu para melhoria no processo de escrita e para mudanças nas concepções pedagógicas da disciplina (Professor/autor K).

A elaboração e sistematização de textos pedagógicos referentes à aula investigativa contribuiu para o meu desenvolvimento profissional, pois elaborar Folhas propiciava estudos, investigação e sistematização que culminavam em mudanças na prática pedagógica. O professor tinha uma formação ativa, partia de sua vivência, de sua experiência (Professor/autor O). 


\section{autêntica}

Para os professores/autores, o processo de elaboração do Folhas traz contribuições para a prática na medida em que torna a aula mais significativa tanto para professor quanto para aluno. Ao elaborar o Folhas, o professor tem a oportunidade de refletir sobre a sua prática, ampliar os seus conhecimentos teóricos e abordar os conteúdos através de novas metodologias de ensino, o que possibilita que a aula seja contextualizada por meio de relação interdisciplinar, com foco na aplicabilidade prática do conteúdo matemático ao cotidiano do aluno, propiciando mudanças na própria prática pedagógica. Assim, nas palavras dos professores/autores, o processo de elaboração do Folhas contribui para a prática pedagógica na medida em que permite a

Promoção de uma prática pedagógica mais investigativa em sala de aula, por meio de atividades que privilegiam a resolução de problemas, pesquisas, a provocação, a mobilização e discussão do conteúdo com os alunos, observando sempre a necessidade de se estabelecer relações interdisciplinares (Professor/autor K).

Reflexão e mudança na prática pedagógica. A partir da escrita dos Folhas passei a tomar mais cuidado com a metodologia de ensino, oportunizando ao aluno investigar os conceitos para depois sistematizá-los (Professor/autor O).

Em relação às contribuições trazidas pelo Folhas às escolas da rede estadual de ensino, os professores/ autores pesquisados argumentam que, nas escolas em que trabalhavam, as suas produções ajudaram: a) no conhecimento do material desenvolvido, que mostrou aos demais professores da escola que existem alternativas para um ensino de Matemática significativo; b) os professores a identificar a possibilidade de trabalhar de forma interdisciplinar os conteúdos de Matemática; c) no reconhecimento do professor como autor de material didático, o que incentivou outros professores a produzirem Folhas; d) na interação entre professores de Matemática e entre professores de Matemática e de outras disciplinas de ensino.

Dessa forma, a ação desenvolvida no processo de elaboração do Folhas caracterizou-se como formação continuada, pois é práxis, tem relação teórico prática; "[...] prática, na medida em que a teoria como guia da ação, molda a atividade do homem, particularmente a atividade revolucionária; teórica, na medida em que essa relação é consciente" (VÁZOUEZ, 1990, p. 117).

As motivações que levaram os professores/autores pesquisados a participar do Projeto Folhas foram diversas: a) ampliação do conhecimento por meio de estudos e pesquisas; b) possibilidade de estudar, aperfeiçoar e desenvolver metodologias de ensino mais práticas que possam tornar o processo de ensino e aprendizagem mais significativo para os alunos; c) oportunidade de escrita dada aos professores pela SEED/PR; d) proposta de trabalho colaborativo entre os professores para a produção de material; e) ação de formação acessível a todos por ser desenvolvida na própria escola; f) incentivos a progressões na carreira do professor por meio de pontuação.

Essas motivações podem ser expressas pelos professores/autores em seus depoimentos:

Ampliar conhecimentos, buscar e aplicar metodologias práticas para sala de aula motivadas por colegas, e também pelo desafio (Professor/autor B).

Por ser um projeto inovador, pelo desafio, pela oportunidade de estudar e compartilhar, aperfeiçoar o fazer pedagógico para proporcionar condições de uma aprendizagem mais significativa para o aluno(a) (Professor/autor C).

Na época, a produção desse material oferecia pontuação que era utilizada na progressão funcional na carreira de professor estadual (Professor/autor D). 


\section{autêntica}

Resolvi participar do Projeto Folhas devido à valorização da produção escrita que ocorria pela Secretaria da Educação do Estado do Paraná durante a gestão do governo Requião (Professor/autor F).

Os textos produzidos apresentam diferenças metodológicas. Conforme o tempo de duração do projeto aumenta, os textos produzidos vão melhorando a consistência teórica, a metodologia e a adequação às exigências dos manuais Folhas.

Apesar de o texto Folhas ter sua estrutura definida pelos manuais (PARANÁ, 2006; 2007), que determinaram a todos o mesmo formato (problema, desenvolvimento teórico, contemporâneo e interdisciplinar, atividades e referências), com orientações do que devia conter cada tópico do texto, há diferentes tendências metodológicas da Educação Matemática permeando as produções. Essa característica do Folhas (autonomia para o professor escrever e utilizar a metodologia que considerava mais adequada) foi um dos atrativos para os professores de Matemática:

Outro fator pelo qual me interessei foi que [o Projeto] deixava o professor livre para a escolha do tema e também porque o formato do Folhas era uma formação continuada que permitia ao professor um papel ativo, não era imposta verticalmente, dando ao professor a oportunidade de escrever aulas a partir da Resolução de Problemas, Investigação Matemática (Professor/autor O).

Isso foi possível devido às próprias orientações da SEED/PR constantes na DCEs de Matemática, que trazem a abordagem dos conteúdos por meio das seguintes tendências: Resolução de Problemas, Modelagem Matemática, Mídias Tecnológicas, Etnomatemática, História da Matemática e Investigações Matemáticas (PARANÁ, 2008).

Além disso, a SEED/PR, ao elaborar o Projeto Folhas, ao pensar os tópicos que compõem o texto, direcionou o trabalho dos professores/autores para o uso das tendências metodológicas da Educação Matemática e, em paralelo ao Folhas, desenvolveu outras ações de formação continuada junto aos professores da rede, no sentido de disseminar e fortalecer essas tendências metodológicas. Foi o caso do DEB-Itinerante e dos Grupos de Estudos, cujos textos abordavam, entre outras, essa questão. Isso refletiu no texto do Folhas, apresentando caráter metodológico diverso.

Em relação ao posicionamento dos professores/autores pesquisados, 13 (87\%) afirmaram utilizar pelo menos uma tendência da Educação Matemática; apenas dois (13\%) não utilizaram nenhuma tendência específica. Entre as tendências citadas por eles, estão: Resolução de Problemas, citada por 07 professores/autores; Modelagem Matemática, citada por 02 professores/autores; Investigações Matemáticas, citada por 04 professores/autores; e História da Matemática, citada por 02.

Das seis tendências metodológicas elencadas nas DCEs da disciplina Matemática, duas são encontradas nos textos analisados. São elas: Modelagem Matemática e Resolução de Problemas, o que corresponde a $50 \%$ das produções. As Mídias Tecnológicas e a História da Matemática são abordadas apenas de forma superficial no interior de alguns textos, e as tendências Investigações Matemáticas e Etnomatemática não são utilizadas pelos professores/autores. A metade restante das produções envolve outra metodologia que, em maior ou menor intensidade, leva ao desenvolvimento da Educação Matemática de forma crítica e colaborativa entre professores e alunos.

Três produções seguem a tendência da Modelagem Matemática. Ao utilizar essa tendência metodológica, os professores/autores do Folhas permitem que o aluno participe da aula, faça as reflexões necessárias, 


\section{autêntica}

generalize os conceitos que foram e estão sendo trabalhados e construa o conhecimento matemático por meio da visão crítica da presença da Matemática nos diferentes contextos.

A Resolução de Problema é utilizada em boa parte das produções analisadas. Para os professores/autores:

A Resolução de Problemas deve permear todo o trabalho com o ensino da Matemática, [...] fazer com que os estudantes busquem a solução, as quais podem ser feitas por meio de leituras, pesquisas, troca de ideias e cálculos (Professor/autor F).

Doze produções Folhas utilizam essa tendência metodológica ao apresentar problemas como forma de introduzir conteúdos. Nelas, os problemas matemáticos são utilizados para fazer relação entre os conhecimentos já assimilados pelos alunos e o conteúdo novo que o professor deseja que aprendam, promovendo assim maior compreensão. Os problemas abordados nos textos revelam a preocupação dos professores/ autores em superar a resolução de exercícios (aplicação de regras, conceitos, fórmulas) na medida em que são uma forma de aprender e compreender os conhecimentos teóricos e práticos da disciplina Matemática.

As outras três tendências constantes nas DCEs (Mídias Tecnológicas, História da Matemática e Investigações Matemáticas) não foram utilizadas em nenhum Folhas. Dez Folhas mencionaram a pesquisa em sites de internet como forma de complementação dos estudos e do próprio texto. Além disso, um Folhas, apenas ao final do texto, apresentou como sugestão o uso de planilha eletrônica para aprofundar o conteúdo. Sete Folhas abordaram superficialmente (na maioria das vezes em menos de uma página do texto) a História da Matemática.

No que se refere às tendências metodológicas utilizadas, estas apresentam uma relação em comum. Todas indicam como ponto de partida para o trabalho em sala de aula a realidade do aluno, as questões do cotidiano e da cultura que possuem significados para a classe. Ou seja, aparece claramente a realidade como princípio metodológico para o ensino da Matemática, pois demostra que as questões oriundas da realidade social mais ampla podem ser problematizadas e, a partir disso, transformadas em objeto de ensino que, para ser compreendido criticamente, necessita dos conhecimentos matemáticos historicamente produzidos e sistematizados transmitidos na escola.

A estruturação do texto Folhas segue os passos propostos pela Pedagogia Histórico-Crítica; aqui, encontram-se mais evidências que corroboram com tal afirmação, uma vez que as tendências metodológicas encontradas tomam como ponto de partida a realidade do aluno, sendo esse também o ponto de partida dessa pedagogia.

O ponto de partida do novo método não será a escola, nem a sala de aula, mas a realidade social mais ampla. A leitura crítica dessa realidade torna possível apontar um novo pensar e agir pedagógicos. Deste enfoque, defende-se o caminhar da realidade social, como um todo, para a especificidade teórica da sala de aula e desta para a totalidade social novamente, tornando possível um rico processo dialético de trabalho pedagógico (GASPARIN, 2005, p. 3-4).

As produções Folhas foram elaboradas por professores com a principal preocupação de iniciar o trabalho com os conteúdos a partir de uma problemática que remetesse ao cotidiano do aluno: "Possibilidade de iniciar o conteúdo com uma abordagem diferente" (Professor/autor G). Só que, desde o princípio até os dias atuais, o Folhas constitui material didático para os professores de toda a rede. Nesse contexto, ao elaborar 
o Folhas e ao utilizá-lo, o professor parte de uma situação-problema que já está posta, que supostamente corresponde à realidade vivenciada pelos alunos, mas não é a própria realidade.

Diante dessa suposição, a realidade posta na escola traz como maior dificuldade para os professores, no desenvolvimento de suas aulas pautadas nessas tendências metodológicas, o trabalho a partir de temas problematizados pelos estudantes, uma vez que estes nem sempre vêm ao encontro do currículo escolar instituído. A esse respeito, Gasparin argumenta:

Levando-se em conta que as escolas trabalham com disciplinas definidas pelo currículo, e que o conteúdo de cada uma dela é sempre previamente estabelecido e aprovado pelo corpo docente e pelos órgãos competentes, antes do início das aulas, torna-se difícil, para não dizer impraticável, estabelecer primeiramente quais questões sociais serão estudadas e, em função delas, quais os conteúdos mais significativos como resposta (GASPARIN, 2005, p. 37-38).

Assim, em sala de aula, são necessárias adaptações que permitam o trabalho do conteúdo programático a partir de questões mais amplas que levem o aluno ao desenvolvimento crítico. Para além disso, ousa-se sugerir a alteração dos currículos das escolas para que deixem de ser determinados pelas Secretarias de Educação e passem a ser organizados pelos professores, tendo como fundamento a prática social no momento histórico atual. Ou seja, o professor, de acordo com as necessidades sociais, precisa "[...] selecionar os conhecimentos historicamente produzidos que mais adequadamente satisfaçam as exigências do grupo" (GASPARIN, 2005, p. 39).

Do total de 30 Folhas, a metade utilizou as tendências metodológicas apresentadas pela SEED/PR como alternativas para o encaminhamento metodológico das aulas de Matemática. O restante das produções não utilizou nenhuma das tendências da Educação Matemática. Os professores/autores desses textos procuraram seguir as orientações para elaboração constantes nos manuais organizados pela SEED/PR, com proposta para fomentar a relação interdisciplinar, o trabalho com pesquisa e a valorização do conteúdo, do professor e do aluno enquanto sujeitos ativos do processo de construção e assimilação do conhecimento matemático historicamente produzido pela humanidade.

O que diferencia tais produções Folhas das demais é que nelas foram abordadas atividades com maior preponderância de exercícios de aplicação de conteúdos, fórmulas e regras do que naquelas que utilizam uma tendência da Educação Matemática específica. Contudo, não se afirma que os exercícios não são importantes no processo de ensino-aprendizagem, pois o ser humano aprende repetindo e refletindo sobre o conhecimento já produzido por aqueles que o antecederam. Assim, a repetição também é uma atividade importante para a aprendizagem, pois "[...] faz-se mister repetir muitas vezes determinados atos até que eles se fixem" (SAVIANI, 2005, p. 21). Para o autor, só há aprendizagem quando ocorre a automatização do uso dos conteúdos, quando ele se torna um habitus em que o sujeito se apoia para compreender e agir sobre a realidade.

Os aspectos levantados em relação às metodologias utilizadas pelos Folhas permitem argumentar que as diferentes tendências metodológicas da Educação Matemática não esgotam todas as possibilidades do processo de ensino-aprendizagem em si mesmas, por isso, na prática, complementam-se, podendo o professor, em suas aulas, lançar mão das diferentes tendências para trabalhar um determinado conteúdo. 


\section{autêntica}

\section{ALGUMAS CONSIDERAÇÕES}

Os Folhas explicitam a preocupação, por parte dos professores/autores, com a aprendizagem, o que demonstra ênfase nos conteúdos escolares. Porém, esse fato não enquadra o Projeto nas metodologias tradicionais de ensino, em que o professor assume papel de transmissor de um conteúdo pronto e indiscutível, e o aluno, de receptor passivo. No contexto do Folhas, professores e alunos são protagonistas do processo de ensino, e a construção do conhecimento dá-se a partir de situações problemáticas do cotidiano. Isso se evidencia no fato de que o Projeto traz, em seu bojo, forte alinhamento com a Pedagogia Histórico-Crítica, o que é comprovado pela semelhança entre os passos do método de ensino proposto por Saviani e os itens obrigatórios do texto Folhas.

Embora a estrutura do texto que constitui as produções Folhas siga os passos propostos pela Pedagogia Histórico-Crítica, há algumas contradições, como: a problemática inicial do texto está posta independente da turma, com a suposição de que corresponde à realidade vivenciada pelos alunos. Há dificuldade em trabalhar com as tendências metodológicas da Educação Matemática, justamente em relação à problematização da realidade por parte dos alunos, pois nem sempre vêm ao encontro do currículo escolar instituído. Assim, para que o professor possa trabalhar com as tendências metodológicas na escola, são necessárias adaptações que permitam o desenvolvimento do conteúdo programático a partir de questões mais amplas que levem o aluno ao desenvolvimento crítico. Nesse ínterim, o Folhas se apresenta como uma boa opção.

O Projeto Folhas, na área de Matemática, foi uma proposta muito importante que se configurou como recurso didático e de formação continuada de professores. Como recurso didático, incentiva a participação ativa e consciente dos alunos sem deixar de lado o papel do professor. Como formação continuada, proporciona a reflexão sobre a prática como forma de compreender os seus determinantes, a pesquisa, o estudo, a escola como locus de formação e a ação coletiva e colaborativa entre os pares, com vistas a tornar o processo de ensino aprendizagem significativo.

Devido às suas características, o Projeto Folhas proporcionou aos professores de Matemática oportunidade de formação em momentos distintos. Esses momentos podem ser identificados nos manuais produzidos pela Secretaria para orientação na elaboração do texto Folhas, nas 30 produções analisadas e nas afirmações dos professores/autores. São eles: a) produção escrita; b) processo de validação; c) utilização do material, tanto pelo professor que o produziu quanto para o que faz uso do material didático.

Ao escrever Folhas, o professor/autor teve a oportunidade de refletir sobre a sua prática, ampliar conhecimentos. No processo de validação, tanto o validador (nas diferentes instâncias) quanto o professor/autor refletiam sobre os conteúdos da disciplina e sobre os processos de ensino dos conteúdos. A utilização do material permite aos professores relacionar as situações de ensino com situações de aprendizagem.

Diante dessas considerações, o Folhas representou um projeto com ações de formação continuada capaz de propiciar aos professores de Matemática mudanças na prática educativa. A produção escrita que demanda estudos individuais e colaborativos com professores de outras áreas do conhecimento constitui-se em momento de formação e é uma das principais características mencionadas pelos professores/autores como fator de valorização de seus conhecimentos por parte da SEED/PR.

Ao instituir o Folhas como ação que fez parte do programa de formação continuada de professores, a SEED/ PR direciona para o rompimento com a visão da racionalidade técnica historicamente instalada na formação 
de professores de Matemática. Com isso, procura superar a dicotomia histórica entre quem produz conhecimento (universidade) e quem o aplica em sala de aula (professores). Os professores são capazes de produzir conhecimento e material que utilizam no processo de ensino e aprendizagem, contudo, entende-se que não é a produção de um Folhas que pode desenvolver a cultura da produção de material didático por parte dos professores da rede estadual. É necessário que se estabeleçam diversas ações que fomentem a produção de material de ensino, de forma que esse processo seja naturalizado entre os professores da rede. 


\section{autêntica}

\section{REFERÊNCIAS}

ARCO-VERDE, Yvelise Freitas de Souza. Introdução às diretrizes curriculares. Curitiba: SEED/PR, 2004.

BARDIN, Laurence. Análise de conteúdo. São Paulo: Edições 70, 2011.

D'AMBROSıO, Ubiratan. Educação Matemática: da teoria à prática. 20. ed. Campinas, SP: Papirus, 2010.

FIORENTINI, Dario; LORENZATO, Sergio. Investigação em educação matemática: percursos teóricos e metodológicos. 3. ed. Campinas, SP: Autores Associados, 2012.

GASPARIN, João Luiz. Uma didática para a Pedagogia Histórico-Crítica.3. ed. Campinas, SP: Autores Associados, 2005.

NERY, Belmayr Knopki. Projeto Folhas: uma perspectiva de formação continuada de professores - análise no campo curricular de química. Ijuí: UNIJUÍ, 2008. Dissertação (Mestrado em Educação nas Ciências) Programa de Pós-Graduação em Educação nas Ciências, Universidade Regional do Noroeste do Estado do Rio Grande do Sul, ljuí, 2008. Disponível em: <http://bibliodigital.unijui.edu.br:8080/xmlui/bitstream/handle/ 123456789/393/Belmayr\%20Nery.pdf?sequence=1>. Acesso em: 11 nov. 2014.

PARANÁ. Diretrizes curriculares da educação básica. Curitiba: SEED/PR, 2008.

PARANÁ. Manual de Produção do Folhas: Matemática. Curitiba: SEED/PR, 2007.

PARANÁ. Manual de Produção do Folhas. Curitiba: SEED/PR, 2006a. Disponível em: <http://www.uel.br/ pessoal/jneto/gradua/historia/recdida/ManualFolhasJNETO.pdf>. Acesso em: 29 nov. 2014.

PARANÁ. Resolução n. ${ }^{\circ}$ 2.467. Dispõe sobre a pontuação dos eventos de formação e/ou qualificação profissional e produção do professor da Rede Estadual de Educação Básica do Estado do Paraná. Curitiba: 2006b. Disponível em: <http://dspace.c3sl.ufpr.br:8080/dspace/bitstream/handle/1884/16408/Glauco\%20Gomes\%20 de\%20Menezes\%20\%28Tese\%20de\%20doutorado\%29. pdf? sequence=1\&isAllowed=y $\geq$. Acesso em: 19 dez. 2014.

PARANÁ. Relatório de Gestão 2003-2006 do DEB. Curitiba: SEED/PR, 2006c.

SAVIANI, Dermeval. Escola e democracia. 32. ed. Campinas, SP: Autores Associados, 1999.

SAVIANI, Dermeval. Pedagogia Histórico-Crítica. 9. ed. Campinas, SP: Autores Associados, 2005.

VÁZQUEZ, Adolfo Sánchez. Filosofia da práxis. 4. ed. Rio de Janeiro: Paz e Terra, 1990. 
